\title{
Searching Literature: A Challenge For Novice Researchers
}

\author{
Syed Muhammad Zulfiqar Hyder Naqvi
}

\begin{abstract}
Sir/Madam, the significance of a meticulous literature search can never be emphasized enough. It is rightly said that new knowledge is often generated in the process of interpreting and incorporating existing knowledge. ${ }^{1}$ For most scientific conducts and writings therefore, an in-depth literature search is a must. It is defined as 'the methodical investigation of all published sources for information bearing on a usually scientific or technological subject'. ${ }^{2}$ It is a dynamic process that is regarded as the prime step in any research. ${ }^{3}$ Its fundamental aims are familiarization with the current body of pertinent literature and identification of any gaps that may exist within it. The major challenge in understanding the literature review process is to unlock a researcher's commitment with the literature. ${ }^{4}$ Apart from persistence, patience, and a strong and consistent desire to explore, a comprehensive literature search also requires familiarity with various literature search techniques as interpretation and comprehension are immanent in the literature review process. ${ }^{4}$ Though majority of healthcare practitioners do not have the skills to conduct a research themselves, the knowledge to understand and use available evidence is nevertheless needed. ${ }^{5}$ But unfortunately, it is often observed that many novice researchers get overwhelmed by, or underestimate the importance of, an exhaustive research process as this skill is often taught on an as-needed basis. Therefore, such researchers often lack enough relevant knowledge or comprehension to cope with its various challenges. In any case, such an approach may bear the untoward consequence of a search that is conducted without thoroughness and as a result, pertinent literature may be partially overlooked or completely missed making the whole exercise pointless to a great extent. In order to do justice to
\end{abstract}

any such endeavor, newcomers in the field of scientific research must equip themselves with the required understanding and expertise before attempting to undertake such an arduous task on their own. Making comprehensive use of available learning resources such as instead of depending entirely on abstracts accessing complete articles whenever possible, instead of relying solely on electronic websites searching manually in the libraries and trying to discern the references given at the end of pertinent articles in order to get good ideas about other sources of relevant literature ${ }^{6}$; exploring the avenues of self-learning and education; and associating with experienced peers are suggested as the solutions of meeting with the demands of an exemplary literature search process.

\section{REFERENCES:}

1. Vom Brocke J, Simons A, Niehaves B, Riemer K, Plattfaut $\mathrm{R}$, Cleven A. Reconstructing the giant: On the importance of rigour in documenting the literature search process. InEcis 2009; 9: 2206-17.

2. Literature search: Merriam-Webster; [cited 2019 4th April]. Available from: https://www.merriamwebster.com/dictionary/literature $\% 20$ search.

3. Thakre SB. Electronic biomedical literature search for budding researcher. Journal of clinical and diagnostic research: JCDR. 2013;7(9):2033.

4. Boell SK, Cecez-Kecmanovic D. A hermeneutic approach for conducting literature reviews and literature searches. CAIS. 2014;34:12.

5. Moule P, Hek G. Making sense of research: an introduction for health and social care practitioners. Sage; 2011 Feb 11.

6. Jesson J, Lacey F. How to do (or not to do) a critical literature review. Pharmacy Education. 2006 Jun;6(2):139-48.

\section{$\bullet \bullet \nless \bullet \bullet$}

Syed Muhammad Zulfiqar Hyder Naqvi
Assistant Professor,
Baqai Medical University, Karachi
Received: $12-04-2019$
Accepted: 23-05-2019
$----\ldots-\ldots-\ldots-\ldots-\ldots-\ldots-\ldots-\ldots$ 